\title{
Neoadjuvant continuous infusion of weekly 5-fluorouracil and escalating doses of oxaliplatin plus concurrent radiation in locally advanced oesophageal squamous cell carcinoma: results of a phase I/II trial
}

\section{S Lorenzen', B Brücher ${ }^{2}$, F Zimmermann ${ }^{3}$, H Geinitz ${ }^{3}$, J Riera ${ }^{4}$, T Schuster ${ }^{5}$, N Roethling ${ }^{6}$, H Höfler ${ }^{7}$, K Ott $^{8}$, C Peschel', JR Siewert', M Molls ${ }^{3}$ and F Lordick ${ }^{*}, 10$}

'Third Department of Internal Medicine (Haematology/Medical Oncology), Klinikum rechts der Isar, Technical University of Munich, Munich, Germany; ${ }^{2}$ Department of Surgery, University of Tübingen, Tübingen, Germany; ${ }^{3}$ Department of Radiation Oncology, Klinikum rechts der Isar, Technical University of Munich, Munich, Germany; ${ }^{4}$ Department of Hematology and Oncology, University Hospital Gießen-Marburg GmbH, Marburg, Germany; ${ }^{5}$ Institute of Medical Statistics and Epidemiology, Technical University of Munich, Munich, Germany; ${ }^{6}$ Klinikum rechts der Isar, Technical University of Munich, Munich Center for Clinical Studies, Munich, Germany; ${ }^{7}$ Institute of Pathology, Technical University of Munich, Munich, Germany; ${ }^{8}$ Department of Surgery, University of Heidelberg, Heidelberg, Germany; ${ }^{9}$ Board of Directors of the University Hospital, University of Heidelberg, Heidelberg, Germany;

${ }^{10}$ Department of Medical Oncology, National Centre for Tumour Diseases, University of Heidelberg, Heidelberg, Germany

Oxaliplatin and 5-fluorouracil have a significant activity in locally advanced oesophageal squamous cell cancer (OSCC). However, their optimal dosage and efficacy when combined with concurrent radiotherapy as neoadjuvant treatment are unknown. This non-randomised, phase I/II study aimed to define the maximum tolerated dose (MTD) and assessed the histopathological tumour response rate to neoadjuvant oxaliplatin in weekly escalating doses $\left(40,45,50 \mathrm{mg} \mathrm{m}^{-2}\right)$ and continuous infusional 5-fluorouracil (Cl-5FU; $225 \mathrm{mg} \mathrm{m}^{-2}$ ) plus concurrent radiotherapy. Patients had resectable OSCC. Resection was scheduled for 4-6 weeks after

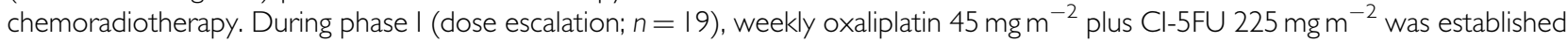
as the MTD and was the recommended dosage for phase II. Oesophageal mucositis was the dose-limiting toxicity at higher doses. During phase II, histopathological responses ( $<10 \%$ residual tumour cells within the specimen) were observed in 10 of 16 patients (63\%; 95\% confidence interval: 39-82\%). Overall, 16 of the 25 patients (64\%) who underwent resection had a histopathological response; tumour-free resection (R0) was achieved in $80 \%$. Neoadjuvant weekly oxaliplatin $45 \mathrm{mg} \mathrm{m}^{-2}$ plus Cl-5FU $225 \mathrm{mg} \mathrm{m}^{-2}$ with concurrent radiotherapy provides promising histological response rates and R0 resection rates in locally advanced OSCC. British Journal of Cancer (2008) 99, 1020 - 1026. doi:10.1038/sj.bjc.6604659 www.bjcancer.com

Published online 16 September 2008

(c) 2008 Cancer Research UK

Keywords: 5-fluorouracil; chemoradiotherapy; neoadjuvant; oesophageal carcinoma; oxaliplatin; response

Although the best treatment strategy for locally advanced oesophageal squamous cell cancer (OSCC) is still being debated, the use of neoadjuvant chemoradiotherapy has gained acceptance (Gebski et al, 2007; Tepper et al, 2008). The rationale for chemoradiotherapy followed by surgery is potentially to downsize the tumour, thereby increasing the rate of tumour-free (R0) resections, reducing early relapses and improving survival. Overall, the impact of pre-operative treatment on survival depends on achieving a major pathological response at oesophagectomy (Swisher et al, 2005; Brücher et al, 2006). Pathological complete responses are associated with improved long-term survival but

*Correspondence: Dr F Lordick, Department of Medical Oncology, National Centre for Tumour Diseases, University of Heidelberg, Im Neuenheimer Feld 350, D-69|20 Heidelberg, Germany;

E-mail: florian.lordick@med.uni-heidelberg.de

Received 9 May 2008; revised 12 July 2008; accepted 18 August 2008; published online 16 September 2008 occur in only $20-40 \%$ of patients after pre-operative chemoradiotherapy (Bates et al, 1996; Walsh et al, 1996; Bosset et al, 1997; Ajani et al, 2001).

The most widely used pre-operative chemoradiotherapy combination - cisplatin and 5-fluorouracil (5FU) with concurrent radiotherapy - has failed to achieve a histopathological complete response rate above $30 \%$ or a long-term survival rate higher than $40 \%$ in patients with OSCC. Besides limited efficacy, this regimen is associated with substantial gastrointestinal toxicities, including nausea, mucositis and oesophagitis (Herskovic et al, 1992; Al-Sarraf et al, 1997). To enhance the efficacy and tolerability of multimodal treatment, new chemotherapeutic agents, such as oxaliplatin, have been incorporated into oesophageal cancer therapy.

Oxaliplatin is a potent radiosensitising agent both in vitro and in clinical practice (Blackstock et al, 1999; Cividalli et al, 2002; McMullen and Blackstock, 2002; Magne et al, 2003), and phase I and II trials suggest that it is at least as effective as cisplatin in OSCC whereas being better tolerated (Khushalani et al, 2002). If the goal of preoperative radiochemotherapy is to maximise tumour 
shrinkage before surgery, chemotherapy should be scheduled as dense as possible (that is, applied concomitantly and as often as possible during RT), to optimise local effects by sensitising tumour cells to radiation. The use of a weekly oxaliplatin schedule may, in addition, reduce acute toxicity and maximise the inhibition of sublethal radiation-induced DNA damage repair (Aschele et al, 2005). Addition of weekly oxaliplatin to continuous 5-FU or capecitabine and concomitant radiotherapy has been shown to be feasible and active in phase I and II studies in rectal cancer (Machiels et al, 2005; Rutten et al, 2006, Rödel et al, 2007). Moreover, the weekly application of oxaliplatin plus infusional $5 \mathrm{FU} /$ folinic acid has also proven to be highly active in first-line metastatic colorectal (Porschen et al, 2007) and gastric cancer (Lordick et al, 2005). Of note, this regimen is also associated with an acceptable toxicity profile with a particularly low rate of sensory neuropathy (Grothey et al, 2002). Consequently, we conducted this study to define the maximum tolerated dose (MTD) of weekly oxaliplatin with continuous infusional 5FU (CI-5FU) plus concurrent radiotherapy in OSCC, and to assess the clinical activity at the recommended dose level (RDL).

\section{MATERIALS AND METHODS}

This multicentre study was conducted at two institutions in Germany. The protocol was approved by the local ethics committee and the study was performed in accordance with the Declaration of Helsinki. All patients provided written informed consent.

In the phase I and II portion, patients (aged 18-70 years) with histologically confirmed, locally advanced, non-metastatic OSCC (cT2-4 N0-N + M0) were eligible. All were candidates for curative surgery, with a Bartel score $<21$ (Bartels et al, 1998), no prior chemotherapy or radiotherapy and adequate organ function. Exclusion criteria included: oesophageal stent implantation, tracheobronchial tree invasion, tracheobronchial fistula, a second malignancy, uncontrolled infection, neuropathy grade $>1$ or congestive heart failure of New York Heart Association grade $\geqslant 2$.

\section{Study design}

This was an open-label, non-randomised, phase I/II study. Initially, at least three patients were entered at each dose level (DL). Toxicities were recorded at each DL using the National Cancer Institute Common Toxicity Criteria version 2.0. A doselimiting toxicity (DLT) was defined as any adverse event (AE) of grade $\geqslant 3$ clearly related to chemoradiotherapy. If no DLT was found, dose escalation was permitted. If any DLT occurred in the first three patients, three additional patients were treated at the same dose. If a DLT was then noted in one or more patients, no further dose escalation was permitted. The MTD was the highest dose at which fewer than two out of six patients experienced DLTs during chemoradiotherapy and/or in the immediate pre-operative phase. This DL was chosen as the RDL for phase II.

\section{Treatment plan}

Chemotherapy consisted of escalating doses of weekly oxaliplatin (DL 1: $40 \mathrm{mg} \mathrm{m}^{-2}$; DL 2: $45 \mathrm{mg} \mathrm{m}^{-2}$; DL 3: $50 \mathrm{mg} \mathrm{m}^{-2}$ (Figure 1 Flow diagram); Supplementary Table A and Supplementary Figure A). Oxaliplatin was administered by intravenous infusion over $2 \mathrm{~h}$ every week for 5 weeks, and CI-5FU $225 \mathrm{mg} \mathrm{m}^{-2}$ was administered by 24 -h continuous infusion on days $1-33$.

Radiotherapy was administered for 5 days every week for 5 weeks at a dose of $1.8 \mathrm{~Gy} /$ day to the isocentre or a normalisation point that was representative of the target volume, up to a total dose of $45 \mathrm{~Gy}$.
3D conformal external-beam radiotherapy with $6-15 \mathrm{MeV}$ photons was delivered using three- and four-field techniques. The clinical target volume (CTV) comprised the primary tumour and adjacent lymph nodes with a margin of $4 \mathrm{~cm}$ in the craniocaudal direction. For cervical cancers the cervical lymph nodes up to the hyoid including the medial part of the paraclavicular lymph nodes had to be included. For tumours in the mid oesophagus lymph nodes in the upper anterior and posterior mediastinum were included in the CTV if they were suspicious for infiltration on $\mathrm{CT}$ and/or endosonography. For tumours in the lower third lymph nodes along the minor gastric curve and around the coeliac trunk were enclosed if they were suspicious on imaging.

The margin of the planning target volume to the CTV was $8-10 \mathrm{~mm}$ in all directions, taking internal organ movements as well as set up errors into account (Supplementary Table B).

Surgery was scheduled for 4-6 weeks after completion of chemoradiotherapy. Patients underwent standardised, transthoracic, en-bloc oesophagectomy with two-field lymphadenectomy (Siewert et al, 1998). Cervical tumours were treated with a partial oesophageal resection and reconstruction was carried out with a free jejunal graft (Steinau et al, 1988).

Patients were examined at 3, 6, 9 and 12 months and every 6 months thereafter. Assessment included physical examination, laboratory investigations, endoscopy, abdominal ultrasonography and computed tomography of the neck, chest and abdomen.

\section{Treatment-related morbidity and mortality}

Any complication occurring after surgery was considered as postoperative morbidity, including clinically symptomatic anastomotic leakage, pulmonary, cardiovascular, infectious, and miscellaneous events. The overall postoperative mortality rate was defined as any death that occurred before a patient was discharged or even after discharge if there was any possible correlation with the operation itself.

\section{Histopathological work-up}

Response to chemoradiotherapy was classified by quantification of residual tumour cells as follows: no residual tumour cells (complete regression, ypCR); $<10 \%$ viable tumour cells (subtotal regression, ypSR); $10-50 \%$ viable tumour cells (partial regression, ypPR); $>50 \%$ viable tumour cells (minimal regression) (Becker et al, 2003; Brücher et al, 2006). Histopathological response to radiochemotherapy was defined as $<10 \%$ residual tumour cells, whereas histopathological non-response was defined as $>10 \%$ residual tumour.

\section{Statistical analysis}

The primary end point of the phase I part of the study was to define the MTD for oxaliplatin and CI-5FU plus radiotherapy; the primary objective of phase II was the histopathological response rate, defined as a complete or a subtotal histopathological response. The phase II study was designed as a Gehan two-stage trial (Gehan, 1961), assuming a response rate of $\geqslant 50 \%$. With a power of $95 \%$, a sample size of five was required for the first stage. The sample size for the second stage was determined by the observed number of responses and the pre-specified precision of $10 \%$.

Secondary study end points included clinical response rate, tolerability, completeness of tumour resection (R0 resection $v s \mathrm{R} 1$ or $\mathrm{R} 2$ resection), ypT and ypN categories, operative mortality and median overall survival (OS), event-free survival (EFS). OS and EFS were analysed in the intent-to-treat population and were calculated from the date of study assignment until death (OS) or until documented radiological or endoscopic progression, death or last contact (EFS). The probability of survival was estimated using 


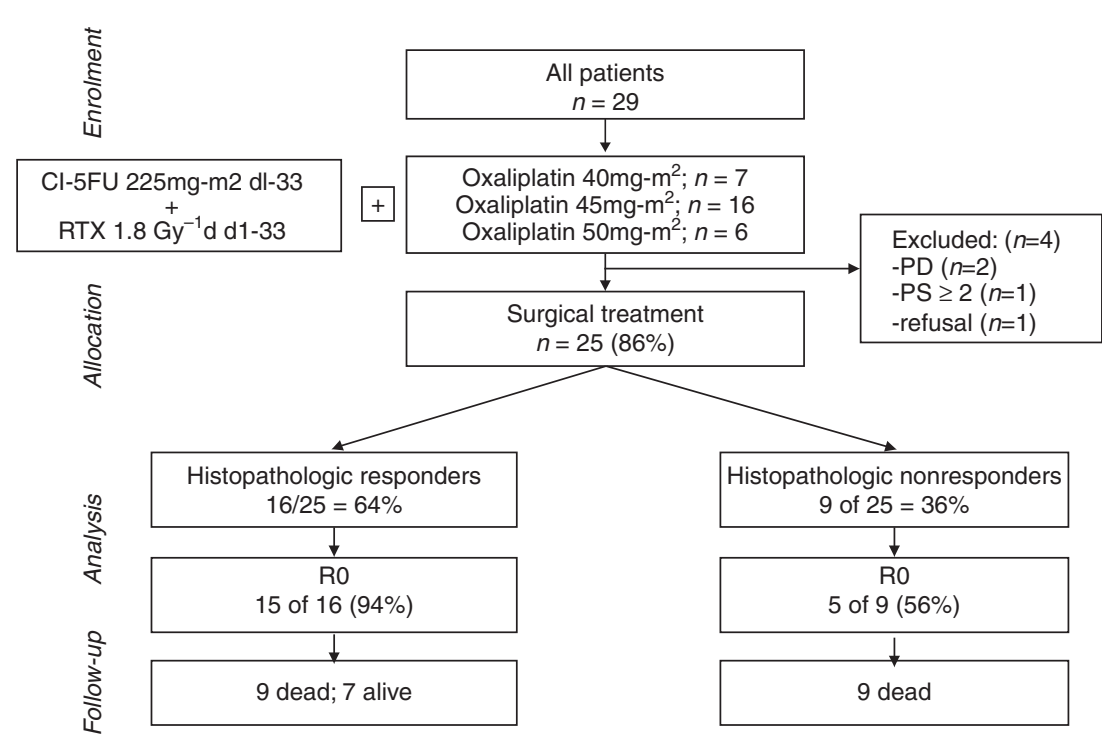

Figure I Flow diagram illustrating the study conduct and patient outcome according to histopathological response.

the Kaplan-Meier method. As the response was defined by histopathological findings available only after surgery, event time analysis comparing histopathlogical responders and non-responders to neoadjuvant therapy was calculated from the day of surgery. Comparisons between patient groups were made by a logrank test. The median survival and hazards ratio calculated by Cox's proportional hazards model were reported with $95 \%$ confidence intervals (CIs). Median follow-up time was calculated by the inverse Kaplan-Meier approach (Schemper and Smith, 1996). The Conditional Binomial Exact Test (Rice, 1988) was used to compare frequencies between patient groups and $95 \%$ confidence intervals for proportions were calculated according to Brown (Brown et al, 2001). All statistical analyses were performed at a 0.05 level of significance.

\section{RESULTS}

\section{Patient characteristics}

From July 2003 to July 2005, 29 patients were enroled (Table 1). All patients received one or more doses of oxaliplatin and CI-5FU plus radiation, and were assessed for response, toxicity and survival.

\section{Dose escalation and DLTs}

Seven patients were treated at DL 1 . One of the first three patients experienced grade 3 mucositis, meeting the criteria for a DLT. Subsequently, four more patients were included, all of whom completed chemoradiotherapy with no DLTs. Owing to simultaneous inclusion of two patients at different study sites, an additional patient was enroled at DL 2; no DLTs were observed in the first three patients. Two of the six patients treated at DL 3 developed grade 3 mucositis needing temporary parenteral nutrition. Consequently, dose escalation was stopped and three additional patients were treated at DL 2, the RDL, one of whom developed grade 3 diarrhoea. Oxaliplatin $45 \mathrm{mg} \mathrm{m}^{-2}$ was therefore selected as the MTD. The RDL cohort was increased to 16 patients for the phase II study.

\section{Treatment delivery}

The median duration of treatment was 5 (range, 3-5) weeks. Overall, 25 of 29 patients completed the planned treatment without
Table I Patient and tumour characteristics

\begin{tabular}{|c|c|c|}
\hline Characteristics & No. of patients $(n=29)$ & $\%$ \\
\hline \multicolumn{3}{|l|}{ Age (years) } \\
\hline Median & \multirow{2}{*}{\multicolumn{2}{|c|}{$\begin{array}{c}60 \\
19-67\end{array}$}} \\
\hline Range & & \\
\hline \multicolumn{3}{|l|}{ Sex } \\
\hline Male & 25 & 86 \\
\hline Female & 4 & 14 \\
\hline \multicolumn{3}{|l|}{ ECOG performance status } \\
\hline 0 & 21 & 72 \\
\hline । & 8 & 28 \\
\hline \multicolumn{3}{|l|}{ Clinical stage $\mathrm{a}^{\mathrm{a}}$} \\
\hline UT2 & 2 & 7 \\
\hline uT3 & 26 & 90 \\
\hline uT4 & । & 3 \\
\hline $\mathrm{uN}+$ & 29 & 100 \\
\hline \multicolumn{3}{|l|}{ Differentiation } \\
\hline Well differentiated (GI) & 0 & 0 \\
\hline Moderately differentiated (G2) & 10 & 35 \\
\hline Poorly differentiated (G3) & 18 & 62 \\
\hline Undifferentiated (G4) & 1 & 3 \\
\hline \multicolumn{3}{|l|}{ Tumour location } \\
\hline Cervical oesophagus & 6 & 21 \\
\hline Mid thoracic & 11 & 38 \\
\hline Lower thoracic & 12 & 41 \\
\hline
\end{tabular}

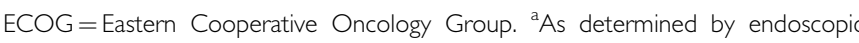
ultrasonography.

interruption; the other four patients did not complete the treatment programme because of excessive toxicity.

\section{Toxicity}

Haematological AEs were mild in the phase I (Supplementary Table C) and II studies (Table 2).

In phase I, one patient had grade 3 diarrhoea and three had grade 3 mucositis. One patient was hospitalised with toxic colitis and grade 3 diarrhoea. Two patients with oesophageal mucositis, 
Table 2 Haematological and non-haematological toxicities (National Cancer Institute Common Toxicity Criteria, version 2.0) observed in the phase II study

\begin{tabular}{|c|c|c|c|c|c|}
\hline \multirow[b]{2}{*}{ Toxicity grade } & \multicolumn{5}{|c|}{ No. of patients $(n=16)$} \\
\hline & I & 2 & 3 & 4 & Total (\%) \\
\hline \multicolumn{6}{|l|}{ Haematological toxicity } \\
\hline Anaemia & 9 & I & - & - & $10(63)$ \\
\hline Neutropenia & 4 & 1 & - & - & $5(3 \mid)$ \\
\hline Febrile neutropenia & - & - & - & - & - \\
\hline Thrombocytopenia & 3 & - & - & - & $3(19)$ \\
\hline \multicolumn{6}{|l|}{ Non-haematological toxicity } \\
\hline Diarrhoea & 5 & I & 1 & - & $8(50)$ \\
\hline Nausea & 6 & I & I & - & $8(50)$ \\
\hline Emesis & 7 & 2 & - & - & $9(56)$ \\
\hline Mucositis within RT field & 5 & 3 & 1 & - & $9(56)$ \\
\hline Mucositis outside RT field & I & - & - & - & I (6) \\
\hline Sensory neuropathy & 6 & 2 & - & - & $8(50)$ \\
\hline Cold-related dysaesthesias & 2 & I & - & - & $3(19)$ \\
\hline Hand-foot syndrome & - & - & । & - & I (6) \\
\hline Lethargy & 10 & 3 & - & - & $13(81)$ \\
\hline
\end{tabular}

$\mathrm{RT}=$ radiotherapy

treated at dose level 3, were hospitalised for intravenous hydration and nutrition.

\section{Histopathological response}

The histopathological response rate (ypCR and ypSR) among all operated patients was $64 \%$ (16 of 25 ; $95 \%$; CI: $43-82 \%$ ). During phase II, histopathological responses were observed in 10 of 16 patients treated at the RDL $(63 \%, 95 \%$ CI: $45-80 \%)$. It is interesting to note that two patients treated at the RDL could not be operated because of disease progression and were therefore considered histopathological non-responders.

\section{Clinical response}

After chemoradiotherapy, the overall response rate according to RECIST was $45 \%$ (13 of 29 patients; 95\% CI: 28.4-62.5\%), including three complete responses (10\%; 95\% CI: 3.6-26.4\%); 14 patients had stable disease (48\%; 95\% CI: 31.4-65.6\%) and two patients had disease progression (7\%; 95\% CI: $1.9-22 \%)$. In the phase II population $(n=16)$, eight patients $(50 \%$; $95 \% \mathrm{CI}$ : $28-72 \%$ ) achieved a response, including three complete remissions. In one patient $(6 \%)$ the disease progressed during treatment (Supplementary Table D).

\section{Surgery}

Overall, 25 patients (86\%) underwent surgery 4-6 weeks after chemoradiotherapy. Four patients did not undergo surgery as a result of disease progression $(n=2)$, deterioration in medical fitness $(n=1)$ and patient refusal $(n=1)$. Among the operated patients, 20 patients $(80 \%)$ underwent $\mathrm{R} 0$ resection and five patients (20\%) underwent R1 resection. No deaths occurred during surgery. The overall postoperative mortality rate was $12.0 \%$ ( 3 of 25 patients; one patient died because of a chylothorax, one because of bleeding, and one because of mediastinitis) (Table 3).

Histopathological responders had a significantly higher R0 resection rate (15 of 16 patients (94\%); 95\% CI: $71.6-98.8 \%$ ) than non-responders (5 of 9 patients (56\%); 95\% CI: $26.7-81.1 \%$; $P=0.023)$
Table 3 Surgical outcome, post-operative morbidity and mortality $(n=25)$

\begin{tabular}{lcc}
\hline Variable & No. of patients & $\%$ \\
\hline Total resections & 25 & 100 \\
Type of resection & & \\
RO & 20 & 80 \\
RI & 5 & 20 \\
Total morbidity & 23 & 92 \\
Anastomotic leakage & 12 & 48 \\
Pulmonary complications & 5 & 20 \\
Necrosis of intestinal interponate & 2 & 8 \\
Bleeding & & 4 \\
Chylothorax & 2 & 4 \\
Retrosternal abscess & 1 & 4 \\
Pleural empyema & $\mid$ & 4 \\
Gastroparesis & 1 & \\
Overall postoperative mortality rate & & \\
\hline
\end{tabular}

\section{Survival}

After a median follow-up of 33.5 months (range, 26.3-48.3 months) from date of study assignment, 7 of the 29 patients $(24 \%)$ were still alive, with no evidence of disease recurrence in six patients (21\%). Two patients developed locoregional, extraluminal recurrences, five had distant recurrences and seven had simultaneous locoregional and distant recurrences.

The median OS was 18 months (95\% CI: 15.8-19.4 months; Supplementary Figure B), with an estimated 2-year survival rate of $28 \%( \pm 8.3 \%)$.

The median EFS was 12.9 months (95\% CI: $10.1-15.7$ months; Supplementary Figure C), with a 2-year EFS rate of $24 \%( \pm 7.9 \%)$.

Comparison between histopathological responders $(n=16)$ and non-responders $(n=9)$ shows a non-significant trend towards a better OS $(P($ log-rank $)=0.21$ Figure 2$)$ and EFS $(P($ log-rank $)=$ 0.11 ; Figure 3 ) in responding patients.

RO resection $(n=20)$ was associated with a significantly improved OS $(P(\log$-rank $)=0.028)$ with a median OS of 16 months (95\% CI: 8.7-23.3 months) vs 9.0 months in patients with incomplete resection ( $n=5$; 95\% CI: 6.8-11.1 months).

\section{DISCUSSION}

This phase I/II study demonstrated that a weekly regimen of neoadjuvant oxaliplatin $45 \mathrm{mg} \mathrm{m}^{-2}$, CI-5FU $225 \mathrm{mg} \mathrm{m}^{-2}$ per day plus concurrent radiotherapy is feasible and effective treatment for patients with locally advanced OSCC, with $>50 \%$ of resected specimens showing major histopathological responses in the primary tumour.

One episode of grade 3 diarrhoea represented the only DLT at the RDL during the phase I dose-escalation study. Overall, clinical toxicities, particularly grade $3 / 4$ haematological and gastrointestinal events, were less intense than previously reported with 5-FUand cisplatin-based chemoradiotherapy (Bedenne et al, 2007). Toxicity assessment in patients treated at the RDL during phase II confirmed the excellent tolerability of the regimen, with mainly mild AEs and only a $6 \%$ overall incidence of grade 3 mucositis and diarrhoea (see Supplementary Table C). This rate of grade 3 mucositis did not exceed that reported previously for cisplatinbased chemoradiotherapy (Heath et al, 2000). Neurotoxicity, a potential concern because of the weekly oxaliplatin administration, consisted mainly of grade 1 events. These findings are comparable with other phase I/II studies using oxaliplatin-based 


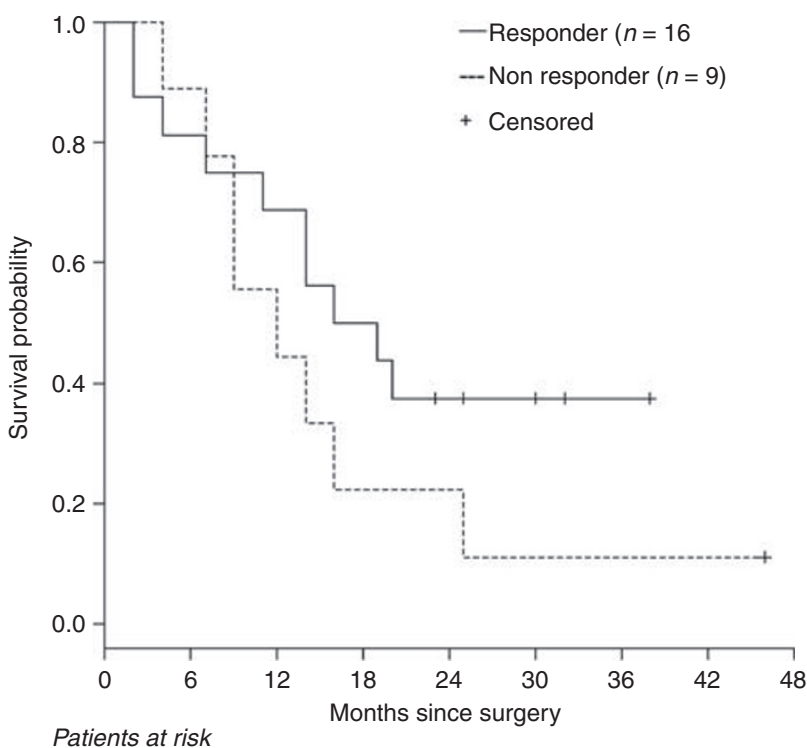

Responder: $\begin{array}{llllllll}13 & 11 & 8 & 5 & 3 & 1 & 0 & 0\end{array}$

$\begin{array}{lllllllll}\text { Non-responder: } 8 & 5 & 2 & 2 & 1 & 1 & 1 & 0\end{array}$

Figure 2 Survival by histopathological response $(P($ log-rank $)=0.2 \mathrm{I}$ vs non-response). Survival is shown for all patients who underwent surgery $(n=25)$. The median OS from date of surgery for histopathological responders was 16 months (95\% confidence interval (Cl): 6.2-25.8 months), respectively, compared with 12 months (95\% Cl: $3.2-20.8$ months) in histopathological non-responders, hazard ratio: $1.78(95 \% \mathrm{Cl}$ $0.70-4.57)$.

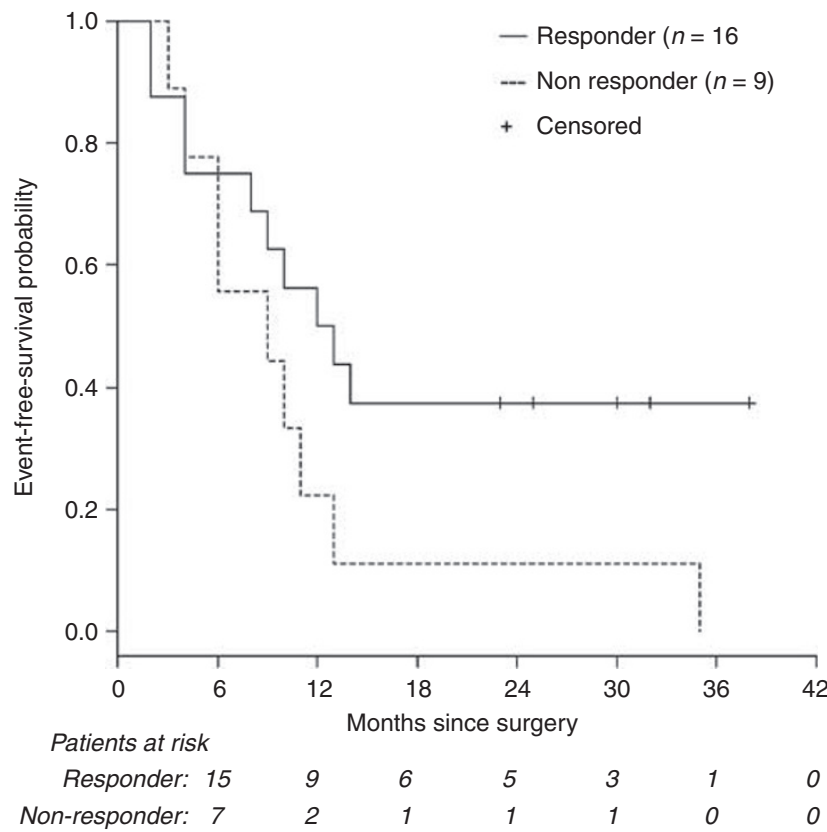

Figure 3 Event-free survival (EFS) by histopathological response ( $P$ (logrank $)=0.1 \mathrm{I})$. EFS is shown for all patients who underwent surgery $(n=25)$. The median EFS from the date of surgery was 12 months in histopathological responders (95\% confidence interval (Cl): 6.1-17.9 months) vs 9 months for non-responders ( $95 \%$ Cl: $0.3-17.8$ months).

chemoradiotherapy (Khushalani et al, 2002; Conroy et al, 2007). The favourable toxicity profile led to good compliance with treatment, and the full radiation course was delivered to all but two patients, and only four patients stopped chemotherapy because of toxicity.
However, a postoperative mortality rate of $12 \%$, although it is in line with data from previous studies in this disease (Stahl et al, 1996, 2005; Van Lanschot et al, 2001) could reflect an important issue hampering satisfying long-term survival in this patient population.

The histopathological response rate of $64 \%$ in all operated patients $(n=25)$ and the histopathological response rate of $63 \%$ observed during phase II $(n=16)$, compare favourably with cisplatin-based neoadjuvant chemoradiotherapy (Bosset et al, 1997; Stahl et al, 2005; Brücher et al, 2006; Bedenne et al, 2007) and oxaliplatin-based chemoradiotherapy given every 2 weeks (Khushalani et al, 2002). This considerable activity may be a result of enhanced radiosensitisation achieved through weekly oxaliplatin administration. Pathological response rates across phase II and III trials vary significantly, so a randomised, comparative study would be required before definitive conclusions can be made regarding the superiority of this regimen over cisplatin-based regimens.

The high histopathological response rate observed would be expected to lead to a high R0 resection rate, which was $94 \%$ in the histopathological responders compared with $56 \%$ in the histopathological non-responders, confirming published data (Brücher et al, 2006). Complete resection, including negative microscopic margins, is a known positive prognostic factor in estimating the survival of patients undergoing oesophagectomy (Kelsen et al, 2007). The overall rate of $80 \%$ for R0 resections reported here in locally advanced disease compares favourably with previously reported rates (Hofstetter et al, 2002; Mariette et al, 2003).

Histopathological response, together with nodal status, appears to be the best predictor of outcomes after chemoradiotherapy (Swisher et al, 2005). However, although the median survival of 18 months was in the range reported previously, the 2-year survival rate of $28 \%$ observed here was suboptimal compared with survival rates reported for cisplatin-based chemoradiotherapy regimens in similar patient populations (Stahl et al, 2005; Bedenne et al, 2007). Moreover, better survival rates were reported with an oxaliplatincontaining chemoradiotherapy regimen in patients with inoperable oesophageal cancer (Conroy et al, 2007). A possible explanation for the relatively low observed 2-year survival rate could be the rather short-term neoadjuvant treatment duration of only 5 weeks in this trial. It is interesting to note that compared with The French Multicenter Study (Bedenne et al, 2007) and the German trial (Stahl et al, 2005) no induction chemotherapy before the start of combined radiochemotherapy was administered. This indicates that, although the current study included a thoroughly staged and uniformly defined population, the optimal treatment for patients presenting with locally advanced OSCC has not yet been defined. The high number of distant relapses may have led to relatively low survival rates and suggests that further refinement of the chemotherapy regimen is warranted. Therefore, intensification of the treatment regimen, for example, by performing a sequential application of a high-dose induction chemotherapy followed by radiochemotherapy, as investigated by Stahl et al (2005) could provide a better control of systemic disease. Also, addition of other chemotherapy drugs like taxanes may add some additional effectiveness (Meluch et al, 2003; van de Schoot et al, 2008).

Overall, neoadjuvant chemoradiotherapy for locally advanced OSCC may improve histopathological response and $\mathrm{R} 0$ resection rates. Nevertheless, the impact of additional surgery on survival is still being debated, with recent phase III trials failing to demonstrate a consistent survival benefit over chemoradiotherapy alone (Stahl et al, 2005; Bedenne et al, 2007).

In conclusion, weekly oxaliplatin, CI-5 FU and conventionally fractionated radiotherapy proved a feasible regimen with a promising pathological response rate and a high $\mathrm{R} 0$ resection rate in a uniform and well-staged group of patients with locally advanced OSCC. However, due to a high distant relapse rate, the 2-year survival rate in this patient population was rather disappointing. 
To optimise treatment further, new targeted agents combined with conventional cytotoxic therapy are being evaluated. In particular, the activity of a weekly regimen of oxaliplatin plus CI-5 FU and radiotherapy with the addition of the epidermal growth factor receptor inhibitor, cetuximab is currently being investigated in a prospective phase II trial in locally advanced OSCC.

\section{ACKNOWLEDGEMENTS}

This study was supported by an unrestricted grant from Sanofi-Aventis Pharma Germany.

Supplementary Information accompanies the paper on British Journal of Cancer website (http://www.nature.com/bjc)

\section{REFERENCES}

Ajani JA, Komaki R, Putnam JB, Walsh G, Nesbitt J, Pisters PW, Lynch PM, Vaporciyan A, Smythe R, Lahoti S, Raijman I, Swisher S, Martin FD, Roth JA (2001) A three-step strategy of induction chemotherapy then chemoradiation followed by surgery in patients with potentially resectable carcinoma of the esophagus or gastroesophageal junction. Cancer 92: 279-286

Al-Sarraf M, Martz K, Herskovic A, Leichman L, Brindle JS, Vaitkevicius VK, Cooper J, Byhardt R, Davis L, Emami B (1997) Progress report of combined radiochemotherapy $v s$ radiotherapy alone in patients with esophageal cancer: an intergroup study. J Clin Oncol 15: 277-284

Aschele C, Friso ML, Pucciarelli S, Lonardi S, Sartor L, Fabris G, Urso ED, Del Bianco P, Sotti G, Lise M, Monfardini S (2005) A phase I-II study of weekly oxaliplatin 5 -fluorouracil continuous infusion and pre-operative radiotherapy in locally advanced rectal cancer. Ann Oncol 16: 1140 - 1146

Bartels H, Stein HJ, Siewert JR (1998) Pre-operative risk analysis and postoperative mortality of oesophagectomy for resectable oesophageal cancer. Br J Surg 85: 840-844

Bates BA, Detterbeck FC, Bernard SA, Qaqish BF, Tepper JE (1996) Concurrent radiation therapy and chemotherapy followed by esophagectomy for localized esophageal carcinoma. J Clin Oncol 14: 156-163

Becker K, Mueller JD, Schumacher C, Ott K, Fink U, Busch R, Böttcher K, Siewert JR, Höfler H (2003) Histomorphology and grading of regression in gastric carcinoma treated with neoadjuvant chemotherapy. Cancer 98: $1521-1530$

Bedenne L, Michel P, Bouche O, Milan C, Mariette C, Conroy T, Pezet D, Roullet B, Seitz JF, Herr JP, Paillot B, Arveux P, Bonnetain F, Binquet C (2007) Chemoradiation followed by surgery compared with chemoradiation alone in squamous cancer of the esophagus: FFCD 9102. J Clin Oncol 25: $1160-1168$

Blackstock AW, Hess S, Chaney S, Tepper JE (1999) Oxaliplatin: in vitro evidence of its radiation sensitizing activity. Pre-clinical observations relevant to clinical trials. Int J Radiat Oncol Biol Phys 45(Suppl 1): $253-$ 254; (Abstract 202)

Bosset JF, Gignoux M, Triboulet JP, Tiret E, Mantion G, Elias D, Lozach P, Ollier JC, Pavy JJ, Mercier M, Sahmoud T (1997) Radiochemotherapy followed by surgery compared with surgery alone in localized squamous cell cancer of the esophagus. N Engl J Med 337: $161-167$

Brown LD, Cai TT, DasGupta A (2001) Interval estimation for a binomial proportion. Stat Sci 16: $101-117$

Brücher BLDM, Becker K, Lordick F, Fink U, Sarbia M, Stein H, Busch R, Zimmermann F, Molls M, Höfler H, Siewert JR (2006) The clinical impact of histopathologic response assessment by residual tumor cell quantification in esophageal squamous cell carcinoma. Cancer 106: 2119-2127

Cividalli A, Ceciarelli F, Livdi E, Altavista P, Cruciani G, Marchetti P, Danesi DT (2002) Radiosensitization by oxaliplatin in a mouse adenocarcinoma: influence of treatment schedule. Int J Radiat Oncol Biol Phys 52: $1092-1098$

Conroy T, Yataghene Y, Etienne PL, Michel P, Senellart H, Raoul JL, Mineur L, Rives M, Mirabel X, Adenis A (2007) Definitive chemo-radiotherapy (CRT) with FOLFOX 4 or 5FU-cisplatin as first line treatment for patients (pts) with inoperable esophageal cancer (IEC): Final results of a randomized phase II study. J Clin Oncol 25(Suppl 18): 4532(Abstract)

Gebski V, Burmeister B, Smithers BM, Foo K, Zalcberg J, Simes J, for the Australasian Gastro-Intestinal Trials Group (2007) Survival benefits from neoadjuvant radiochemotherapy or chemotherapy in oesophageal carcinoma: a meta-analysis. Lancet Oncol 8: 226-234

Gehan EA (1961) The determination of the number of patients required in a preliminary and follow-up trial of a new chemotherapeutic agent. J Chronic Dis 13: 346-353

Grothey A, Deschler M, Kroening H, Ridwelski K, Reichard P, Kretzschmar A, Clemens M, Hirschmann W, Lorenz M, Asperger W, Buechele T, Schmoll HF (2002) Phase III study of bolus 5-fluorouracil (5-FU)/folinic acid (FA) (Mayo) $v s$ weekly high-dose $24 \mathrm{~h} 5$-FU infusion/FA+oxaliplatin (OXA) in advanced colorectal cancer (ACRC). Proc Am Soc Clin Oncol 21: 129a (abstract 512)

Heath EI, Burtness BA, Heitmiller RF, Salem R, Kleinberg L, Knisely JP, Yang SC, Talamini MA, Kaufman HS, Canto MI, Topazian M, Wu TT, Olukayode K, Forastiere AA (2000) Phase II evaluation of pre-operative chemoradiation and postoperative adjuvant chemotherapy for squamous cell and adenocarcinoma of the esophagus. J Clin Oncol 18: $868-876$

Herskovic A, Martz K, al-Sarraf M, Leichman L, Brindle J, Vaitkevicius V, Cooper J, Byhardt R, Davis L, Emami B (1992) Combined chemotherapy and radiotherapy compared with radiotherapy alone in patients with cancer of the esophagus. $N$ Engl J Med 326: 1593-1598

Hofstetter W, Swisher S, Correa A, Hess K, Putnam Jr JB, Ajani JA, Dolormente M, Francisco R, Komaki RR, Lara A, Martin F, Rice DC, Sarabia AJ, Smythe WR, Vaporciyan AA, Walsh GL, Roth JA (2002) Treatment outcomes of resected esophageal cancer. Ann Surg 236: $376-385$

Kelsen DP, Winter KA, Gunderson LL, Mortimer J, Estes NC, Haller DG, Ajani JA, Kocha W, Minsky BD, Roth JA, Willett CG (2007) Long-term results of RTOG Trial 8911 (USA Intergroup 113): a random assignment trial comparison of chemotherapy followed by surgery compared with surgery alone for esophageal cancer. J Clin Oncol 25: $3719-3725$

Khushalani NI, Leichman CG, Proulx G, Nava H, Bodnar L, Klippenstein D, Litwin A, Smith J, Nava E, Pendyala L, Smith P, Greco W, Berdzik J, Douglass H, Leichman L (2002) Oxaliplatin in combination with protracted-infusion fluorouracil and radiation: report of a clinical trial for patients with esophageal cancer. J Clin Oncol 20: 2844-2850

Lordick F, Lorenzen S, Stollfuss J, Vehling-Kaiser U, Kullmann F, Hentrich M, Zumschlinge R, Dietzfelbinger H, Thoedtmann J, Hennig M, Seroneit T, Bredenkamp R, Duyster J, Peschel C (2005) Phase II study of weekly oxaliplatin plus infusional fluorouracil and folinic acid (FUFOX regimen) as first-line treatment in metastatic gastric cancer. $\mathrm{Br} J$ Cancer 93: $190-194$

Machiels JP, Duck L, Honhon B, Coster B, Coche JC, Scalliet P, Humblet Y, Aydin S, Kerger J, Remouchamps V, Canon JL, Van Maele P, Gilbeau L, Laurent S, Kirkove C, Octave-Prignot M, Baurain JF, Kartheuser A, Sempoux C (2005) Phase II study of preoperative oxaliplatin, capecitabine and external beam radiotherapy in patients with rectal cancer: The RadiOxCape Study. Ann Oncol 16: 1898-1905

Magne N, Fischel JL, Formento P, Etienne MC, Dubreuil A, Marcié S, Lagrange JL, Milano G (2003) Oxaliplatin-5-fluorouracil and ionizing radiation. Importance of the sequence and influence of the p53 status. Oncology 64: $280-287$

Mariette C, Finzi L, Fabre S, Balon JM, Van Seuningen I, Triboulet JP (2003) Factors predictive of complete resection of operable esophageal cancer. A prospective study. Ann Thorac Surg 75: 1720-1726

McMullen KP, Blackstock AW (2002) Chemoradiation with novel agents for rectal cancer. Clin Colorectal Cancer 2: 24-30

Meluch A, Greco F, Gray J, Thomas M, Sutton VM, Davis JL, Kalman LA, Shaffer DW, Yost K, Rinaldi DA, Hainsworth JD (2003) Preoperative therapy with concurrent paclitaxel/carboplatin/infusional 5-FU and radiation therapy in locoregional esophageal cancer: final results of a Minnie Pearl Cancer Research Network phase II Trial. Cancer J 9: $251-260$

Porschen R, Arkenau HT, Kubicka S, Greil R, Seufferlein T, Freier W, Kretzschmar A, Graeven U, Grothey A, Hinke A, Schmiegel W, Schmoll HJ, AIO Colorectal Study Group (2007) Phase III study of capecitabine plus oxaliplatin compared with fluorouracil and leucovorin plus oxaliplatin in metastatic colorectal cancer: a final report of the AIO Colorectal Study Group. J Clin Oncol 25: 4217-4223 
Rice WR (1988) A new probability model for determining exact $P$-values for $2 \times 2$ contingency tables when comparing binomial proportions. Biometrics 44: 1 - 14

Rödel C, Liersch T, Hermann RM, Arnold D, Reese T, Hipp M, Fürst A, Schwella N, Bieker M, Hellmich G, Ewald H, Haier J, Lordick F, Flentje M, Sülberg H, Hohenberger W, Sauer R (2007) Multicenter phase II trial of chemoradiation with oxaliplatin for rectal cancer. J Clin Oncol 25: $110-117$

Rutten H, Sebag-Montefiori D, Glynne-Jones R, Rullier E, Peeters M, Brown G, Van Cutsem E, Ricci S, Van de Velde CJ, Quirke P (2006) Capecitabine, oxaliplatin, radiotherapy, and excision (CORE) in patients with MRI-defined locally advanced rectal adenocarcinoma: results of an international multicenter phase II study. J Clin Oncol 24: 153s (suppl; abstract 3528)

Schemper M, Smith TL (1996) A note on quantifying follow-up in studies of failure time. Control Clin Trials 17: 343-346

Siewert JR, Hoelscher AH, Roder ID, Bartels H (1998) En-bloc esophagectomy in esophageal cancer. Langenbecks Arch Chir 373: 367-376

Stahl M, Stuschke M, Lehmann N, Meyer HJ, Walz MK, Seeber S, Klump B, Budach W, Teichmann R, Schmitt M, Schmitt G, Franke C, Wilke H (2005) Chemoradiation with and without surgery in patients with locally advanced squamous cell carcinoma of the esophagus. J Clin Oncol 23: $2310-2317$

Stahl M, Wilke H, Fink U, Stuschke M, Walz MK, Siewert JR, Molls M, Fett W, Makoski HB, Breuer N, Schmidt U, Niebel W, Sack H, Eigler FW, Seeber S (1996) Combined preoperative chemotherapy and radiotherapy in patients with locally advanced esophageal cancer. Interim analysis of a phase II trial. J Clin Oncol 14: 829-837

Steinau HU, Biemer E, Bader M, Holscher M, Siewert JR (1988) Reconstruction of the Cervical Esophagus by Microsurgical Transfer of Intestinal Segment. Springer: New York

Swisher SG, Hofstetter W, Wu TT, Correa AM, Ajani JA, Komaki RR, Chirieac L, Hunt KK, Liao Z, Phan A, Rice DC, Vaporciyan AA, Walsh GL, Roth JA (2005) Proposed revision of the esophageal cancer staging system to accommodate pathologic response ( $\mathrm{pP}$ ) following pre-operative chemoradiation (CRT). Ann Surg 241: 810-820

Tepper J, Krasna MJ, Niedzwiecki D, Hollis D, Reed CE, Goldberg R, Kiel K, Willett C, Sugarbaker D, Mayer R (2008) Phase III trial of trimodality therapy with cisplatin, fluorouracil, radiotherapy, and surgery compared with surgery alone for esophageal cancer: CALGB 9781. J Clin Oncol 26(7): $1086-1092$

van de Schoot L, Romme EA, van der Sangen MJ, Creemers GJ, van Lijnschoten G, van Driel OJ, Rutten HJ, Nieuwenhuijzen GA (2008) A highly active and tolerable neoadjuvant regimen combining paclitaxel, carboplatin, 5-FU, and radiation therapy in patients with stage II and III esophageal cancer. Ann Surg Oncol 15: 88-95

Van Lanschot JJ, Hulscher JB, Buskens CJ, Tilanus HW, ten Kate FJ, Obertop H (2001) Hospital volume and hospital mortality for esophagectomy. Cancer 91: 1574-1578

Walsh T, Noonan N, Hollywood D, Kelly A, Keeling N, Hennessy TP (1996) A comparison of multimodality therapy and surgery for esophageal adenocarcinoma. $N$ Engl J Med 335: 462-467 